\title{
PODER TRANSPORTISTA. NUEVOS LIDERAZGOS AYMARA EN LA FRONTERA DE BOLIVIA Y CHILE*
}

\section{Poder Transportista. New Aymara Leadership on the Border of Bolivia and Chile}

\section{ALEJANDRO GARCÉS** \& JORGE MORAGA***}

\section{Fecha de recepción: 15 de enero de 2018 - Fecha de aprobación: 26 de junio de 2018}

\section{Resumen}

A partir del desarrollo del sistema vial contemporáneo entre Bolivia y Chile, este artículo explora la constitución de un mercado de transporte de mercancías y personas que configura una elite de transportistas aymaras en las localidades de Colchane y Pisiga, que ahora se ve tensionada por la emergencia de nuevos actores nacionales e internacionales. En un contexto de despoblamiento rural, de migración a diferentes ciudades en ambos países, y de declive de la economía agropecuaria, observaremos cómo la participación en este mercado del transporte ha supuesto una importante fuente de acumulación económica en la que se han insertado los actores indígenas, reconfigurando algunas estructuras políticas preexistentes y generando nuevas formas de movilidad social y liderazgo político y económico.

Palabras clave: Colchane-Pisiga; transporte; aymara; economía; frontera.

\section{Abstract}

As of the development of the contemporary road system between Bolivia and Chile, this article explores the formation of a goods and people transportation market, one that shapes an aymara hauliers elite inboth Colchane and Pisiga. This elite is now tensed by the arrival of new national and international actors. Within a context of rural depopulation, migration to different cities in both Chile and Bolivia and farming economy deterioration, we will see how participation in this transportation market has implied an important source of economic accrual in which native actors have got into. This process has reconfigured some preexisting political structures and it has generated some new forms of social mobility and economic and political leadership.

Keywords: Colchane-Pisiga; Aymara; transportation; economy; border.

\footnotetext{
* Este artículo es una versión ampliada y corregida del artículo publicado en inglés en Chungara Revista de Antropología Chilena 2016, 48(3), pp. 441-451.

** Dr. en Antropología Social. Investigador de la Universidad Católica del Norte, San Pedro de Atacama, Chile. El artículo se enmarca en el proyecto FONDECYT 11110246, Chile. Correo-e: agarces@ucn.cl, ajgarces@gmail.com

*** Dr. en Antropología Social. Investigador de la Universidad Central de Chile, Santiago, Chile. Correo-e: jorge.moraga@ucentral.cl
} 


\section{Introducción}

Este artículo se propone caracterizar algunas de las transformaciones sociales, políticas y económicas al interior del mundo aymara -en tanto grupo étnico predominante en la zona- de las localidades colindantes a la frontera nacional en torno al complejo fronterizo en Colchane-Pisiga, que conecta los territorios de la región de Tarapacá en el norte chileno y el departamento de Oruro en el occidente boliviano, las cuales han sido dinamizadas por el importante auge y desarrollo de la economía del transporte de mercancías y personas en las últimas décadas (Ver mapa 1). El trabajo emerge a partir de dos períodos de trabajo etnográfico en las localidades de Colchane, Pisiga Bolivar, Cariquima, Enquelga, Chijo, Pozo Almonte y Alto Hospicio en Iquique, entre enero y marzo de 2013.

Mapa 1: Corredor Iquique (Chile) - Oruro (Bolivia)

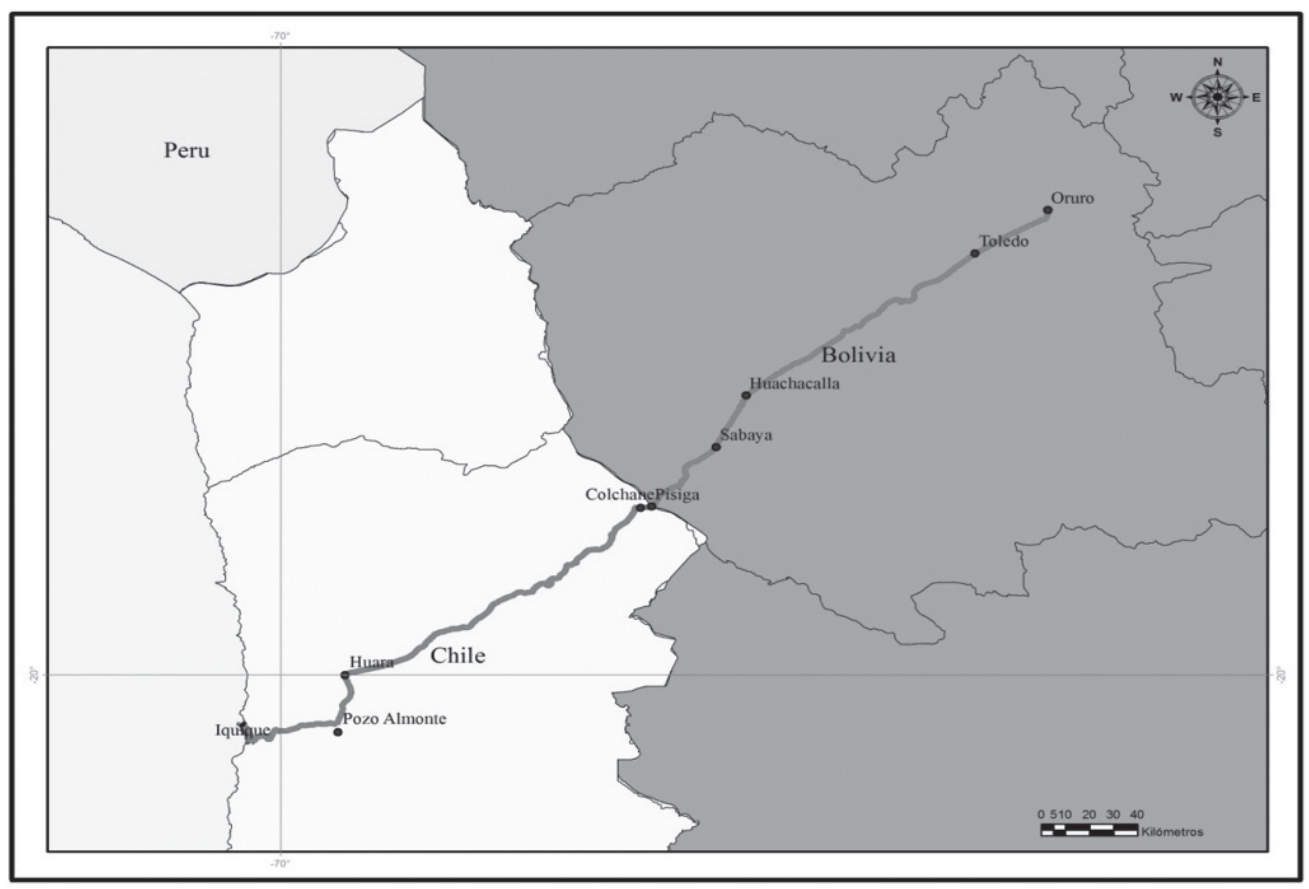

MAPA 1: CORREDOR IQUIQUE - ORURO

Elaboración: Ignacio Manríquez 
Desde que en la década del 80 se pavimenta y mejoran las condiciones de la carretera $15-\mathrm{CH}$ internacional (antes A55), entre la localidad chilena de Huara y el paso fronterizo Colchane-Pisiga, el flujo de personas y mercancías ha experimentado un notable crecimiento. Según las estadísticas de Aduanas de Chile (2012), el flujo apenas alcanzaba en promedio las 85.000 personas entre 1997 y 2004, cuestión que se incrementa notoriamente desde el 2005 en adelante, sobrepasando las 400.000 personas en 2012. En cuanto a las mercancías, medidas en toneladas, según la misma fuente se produce también un notorio incremento que para el año 2012 alcanzaba las 317.330 toneladas. Si bien estos números son inferiores a los que presenta el paso Chungara, que centraliza el tráfico entre La Paz y el puerto de Arica, igualmente dan cuenta de un importante dinamización de los flujos en esta frontera.

Tabla 1. Tráfico Terrestre Fronterizo $\left(\mathrm{n}^{\circ}\right.$ de personas)

\begin{tabular}{|l|r|r|r|r|r|r|r|r|}
\hline Aduanas & \multicolumn{1}{|c|}{2005} & 2006 & 2007 & 2008 & 2009 & 2010 & 2011 & 2012 \\
\hline VISVIRI & 10.575 & 11.372 & 9.409 & 8.134 & 7.033 & 4.115 & 2.942 & 3.473 \\
\hline CHACALLUTA & 3.733 .427 & 4.135 .374 & 4.315 .140 & 4.003 .856 & 4.110 .642 & 4.508 .000 & 5.009 .029 & 5.150 .971 \\
\hline CHUNGARA & 275.515 & 338.184 & 409.925 & 442.906 & 470.471 & 480.266 & 550.015 & 566.945 \\
\hline COLCHANE & $\mathbf{1 5 1 . 7 8 6}$ & $\mathbf{2 1 4 . 3 7 4}$ & $\mathbf{2 4 8 . 1 8 9}$ & $\mathbf{3 0 3 . 8 4 9}$ & $\mathbf{2 9 5 . 3 5 4}$ & $\mathbf{2 8 2 . 7 2 6}$ & $\mathbf{3 1 4 . 2 0 2}$ & $\mathbf{4 3 2 . 5 9 8}$ \\
\hline OLLAGUE & 7.252 & 13.605 & 14.686 & 19.917 & 16.990 & 18.154 & 20.747 & 25.288 \\
\hline
\end{tabular}

Fuente: Síntesis mensual de tráfico fronterizo de Aduanas (Elaboración propia)

Tabla 2. Tráfico Terrestre Fronterizo ( $\mathrm{n}^{\circ}$ de toneladas de carga)

\begin{tabular}{|l|r|r|r|r|r|r|r|r|}
\hline Aduanas & 2005 & 2006 & 2007 & 2008 & 2009 & 2010 & 2011 & 2012 \\
\hline VISVIRI & 36.075 & 42.470 & 62.107 & 49.115 & 32.690 & 18.682 & 5.039 & 5.493 \\
\hline CHACALLUTA & 316.339 & 301.328 & 286.461 & 319.602 & 294.261 & 375.721 & 370.830 & 385.798 \\
\hline CHUNGARA & 999.390 & 1.022 .785 & 1.253 .838 & 1.763 .630 & 1.661 .881 & 2.003 .982 & 2.508 .137 & 2.773 .226 \\
\hline COLCHANE & $\mathbf{7 2 . 0 1 1}$ & $\mathbf{1 3 2 . 2 7 4}$ & $\mathbf{1 7 8 . 2 6 1}$ & $\mathbf{2 3 4 . 5 8 1}$ & $\mathbf{1 9 2 . 5 2 2}$ & $\mathbf{1 7 2 . 7 8 4}$ & $\mathbf{2 2 0 . 3 2 0}$ & $\mathbf{3 1 7 . 3 3 0}$ \\
\hline OLLAGUE & 17.832 & 33.700 & 37.214 & 73.613 & 46.366 & 62.414 & 62.484 & 70.777 \\
\hline
\end{tabular}

Fuente: Síntesis mensual de tráfico fronterizo de Aduanas (Elaboración propia) 
Este trabajo es fruto de una investigación etnográfica en las localidades de Alto Hospicio, Pozo Almonte, Colchane y Pisiga, e iniciada el año 2013. A partir de la observación etnográfica pretendemos dar cuenta de algunas prácticas aymara que en ocasiones son presentadas a priori como una pura estrategia económica, enmarcadas en una lógica racional-utilitaria, pero que en la práctica de los sujetos se encuentran condicionadas por otros dominios de la vida social, que nos remiten a espacios de legitimidad propios del orden político, ritual, comunitario.

El texto distingue dos partes principales. En primer lugar, describimos la emergencia de una elite transportista en Colchane y Pisiga, protagonizada en gran medida por el mundo aymara de la zona, fundamentalmente por parte de familias e individuos que ya poseían cierta posición económica y liderazgo simbólico o ritual al interior de las comunidades. Interesa aquí observar la apropiación y yuxtaposición de los capitales económicos, políticos y simbólicos en estas comunidades, en un vaivén que comprende desde la desestructuración de lo aymara en algunos casos, al reforzamiento de jerarquías tradicionales o históricas. En segundo lugar, abordamos la emergencia de una economía también del transporte pero que es marginal respecto de la acumulación de capital protagonizada por la elite. Ante la competencia que se establece frente a las grandes empresas de transporte, tanto aymaras como chilenas o extranjeras, importantes grupos de personas se han convertido en pequeños emprendedores del transporte, economía que complementan con las actividades tradicionales agropecuarias y con el uso diferenciado de los distintos espacios tanto rurales como urbanos que explotan en el marco de la contemporánea translocalidad del mundo aymara. Con esta distinción, nuestro propósito no es presentar estas economías indí- genas exclusivamente como formaciones tradicionales o no capitalistas, sino ilustrar cómo se coordinan y se apropian de los nuevos contextos capitalistas, nacionales y tecnológicos en los que se encuentran. Como Tassi y otros autores han señalado en el caso de Bolivia, las economías aymaras conducen a la formación de nuevas elites étnicas que se integran con los mercados globales mediante el uso de patrones y estrategias locales, tanto establecidas como contemporáneas. De esta forma, constituyen una crítica de las perspectivas esencialistas que explican estas economías en comparación con los antiguos sistemas de reciprocidad y las relaciones familiares tradicionales (Tassi, Hinojosa \& Canaviri, 2014; Tassi, 2015).

Por otro lado, las relaciones entre transporte y poder, o entre transporte y liderazgos indígenas, presenta por supuesto una historicidad en estas zonas protagonizada por otros medios de transporte. La base animal de estas movilidades, y su papel estructurador en las economías y dinámicas locales se encuentra desarrollada en la literatura arqueológica y antropológico-histórica (Pimentel, Rees, De Souza \& Arancibia, 2011; Richard, Moraga \& Saavedra, 2016; Richard, Galaz-Mandakovic, Carmona \& Hernández, 2018). Sin embargo, la novedad de nuestra aproximación a la dinámica contemporánea de estos procesos, además del tránsito del animal al camión o al autobús, está dada por la ampliación de los espacios y economías que convergen en esta dinámica. La creación de las zonas francas, la movilidad migratoria con una creciente presencia boliviana, y en definitiva el empuje de economías globales, acompañan y determinan, como veremos, la constitución de un nuevo poder transportista y su deriva en los liderazgos locales y diferenciaciones internas a las comunidades indígenas. 
II. La construcción de la elite transportista aymara

Esta sección intentará analizar los mecanismos mediante los cuales se ha consolidado una élite transportista aymara en el marco de la llamada segunda fase del proceso modernizador impulsado en los últimos 40 años en Chile, en especial a partir de la aplicación del modelo neoliberal por la dictadura militar. Esta nueva fase de expansión capitalista ha dirigido los procesos de integración y diferenciación indígena instaurando barreras estructurales que han reconfigurado los procesos locales y parentales de las comunidades aymaras. Estas barreras estructurales han tomado la forma, principalmente, de una nueva institucionalidad que ha tendido a "municipalizar" el espacio andino tanto en Chile como en Bolivia (Gundermann, 2003; Burguete, 2011; Orellana, 1999), a "privatizar y enajenar" los recursos naturales, en especial el agua y los recursos del subsuelo (Yáñez \& Molina, 2008; Perreault, 2006), y a estimular el ingreso de los sujetos de estas comunidades en políticas de emprendimiento particulares comandadas por las necesidades del comercio y los capitales nacionales y transnacionales ${ }^{1}$. Se ha conformado así una profunda reorganización del sistema andino, la cual no puede ser comprendida como pura desestructuración ni pura continuidad o anclaje en la tradición, sino más bien como siguiendo una dinámica, a la vez de cambio y de recomposición entendidos como dos aspectos de un mismo conjunto de fenómenos (Gundermann, 2003).

Estos reajustes estructurales derivaron hacia dos fenómenos entrelazados que han reconfigurado el paisaje indígena permitiendo la consolidación del comercio transportista: la gran migración de la población altiplánica hacia las ciudades de la costa, en especial en la década de 1990, y la reintegración de los espacios locales en prácticas que tendieron a aumentar su heterogeneidad y complejidad social. Estos fenómenos se vieron impulsados por el creciente comercio en torno a la Zona Franca de lquique (Zofri), la cual si bien fue fundada en 1975, cobra fuerza en esta zona solo a partir de la década de 1990 debido a la flexibilización de los permisos para el ingreso de camiones bolivianos, la creación en Bolivia de la Zona Franca de Oruro (Zofro, en 1991) y el mayor flujo de mercancías derivado de mejoras sustanciales en la Ruta A-55 (15-CH Internacional) entre las localidades de Huara y el paso fronterizo de Colchane/Pisiga, que se terminó de pavimentar en la década del 2000. La pavimentación del tramo final en el sector boliviano fue inaugurada por Evo Morales el 2012.

Observando que las comunidades aymaras no se han presentado como actores pasivos ante este proceso de cambios, indagaremos en los mecanismos de conformación de las actuales élites transportistas, en su necesidad de adaptación y resignificación de dichos marcos estructurantes, élites que tienden a condensar -no exentas de fricciones- tanto el poder económico y político local, además de comandar los procesos de reconfiguración étnica y religiosa en la comuna de Colchane. Intentaremos probar que estas élites han logrado mantener e incluso potenciar su hegemonía del poder local (en Bolivia y Chile) articulando en su provecho tanto las relaciones de reconocimiento "igualitario" en el marco del poder simbólico-político nacional, como las relaciones "jerárquicas" de subordinaciones y deudas que han establecido tradicionalmente al interior de sus comunidades étnicas. La distinción entre relaciones jerárquicas y reconocimiento igualitario, que presenta- 
mos entre comillas, tienden a omitir la multiplicidad de matices en los cuales se manifiesta la imbricación de los campos económico, social y político, diluyendo asimismo la hegemónica dicotomía entre modernidad y tradición.

Las historias familiares de conformación y acumulación de capital económico nos permiten observar la emergencia de estos procesos. Los casos más significativos de concentración y hegemonía familiar del poder se dibujan en las trayectorias de los García Mamani y Choque en territorio chileno, y los Colque en el boliviano. En los tres ejemplos queda expuesta la experiencia de translocalidad que caracteriza el momento contemporáneo, explicitándose la necesidad de trasladarse a otras ciudades chilenas o bolivianas para comenzar el proceso de obtención y acumulación de capital simbólico y económico (Bourdieu, 1997), ya sea mediante estudios, contactos laborales o negocios.

Entre los aymara-bolivianos, Eddie Colque es dueño de la principal empresa de transportes de Pisiga-Bolívar (Bolivia) y miembro de una cooperativa del rubro. Recuerda su infancia en la que compartía con los aymaras del lado chileno (hoy importantes autoridades políticas y "transportistas", según dice) y menciona, no desprovisto de orgullo, que él es agrónomo y que comenzó sus estudios en la Universidad de Tarapacá (Chile):

Al alcalde [de Colchane], Teófilo [Mamani]... lo conozco de niño. Él fue transportista pues. Yo fui agrónomo. Yo soy ingeniero agrónomo [...] Conozco la universidad de lquique, porque yo ahí tenía que estudiar yo... pero como eran los gastos un poco... muy elevados, entonces de ese modo yo me quedé [estudiando] aquí en Bolivia. (Entrevista con Eddie, 10 de febrero 2013)
Colque ejerció el poder alcaldicio de Pisiga-Bolívar entre 2009 y 2012. En la actualidad es reconocido como el jilakata ${ }^{2}$ del lugar, una autoridad tradicional aymara equivalente a los caciques que intentan posicionase en el sector chileno. En marzo de 2013 protagonizó una ocupación de las oficinas aduaneras del complejo fronterizo de Colchane-Pisiga, protestando junto a un grupo de transportistas y otras autoridades tradicionales (entre ellas su pariente, el corregidor Ludger Colque) por el cambio de los funcionarios en la aduana de Pisiga, quienes -según denunciaban- obstaculizaban la expedita introducción de mercancías desde la Zofri.

Entre los aymara-chilenos, David García Mamani, miembro de la familia dueña de "Transportes García”, reafirma la necesaria etapa de acumulación de capital económico en la ciudad. Su familia logró manejar una cadena de carnicerías en Alto Hospicio, articulando contactos con proveedores en Osorno, Lo Valledor (Santiago), Paraguay, Argentina e incluso Estados Unidos. Trabajó en el negocio familiar de las carnes hasta el año 2009, cuando decidió reunir parte del patrimonio y volver a su tierra, el altiplano de Colchane, donde instaló un hotel para explorar en el rubro del turismo:

Trabajaba en (...) una de las carnicerías que tenía,
administraba la carnicería y eso, actualmente están
mis hermanos allá trabajando, o sea, se estableció
más menos el rubro, llevamos más de 20 años con el
rubro, así que, un poco satura también, porque hay que
estar ahí todos los días. (Entrevista con David, 12 de
febrero de 2013)

La historia de "Transportes García" es paradigmática. El año 1994 comenzaron con el trasporte rural de pasajeros entre lquique $y$ Colchane. Hacia fines de esa década, apro- 
vechando el explosivo poblamiento de Alto Hospicio, pusieron dos pequeños taxibuses a recorrer los 12 kilómetros y el gigantesco acantilado que separa esta localidad del puerto de lquique. Fundaron en ese momento una asociación gremial: "Transatélite A.G." y el 2004, con la creación oficial de Alto Hospicio, obtuvieron la concesión del trasporte en la comuna. En la actualidad tienen una importante flota de transporte de pasajeros para las minas Collahuasi, Gaby y Zaldívar, entre otras.

También vinculada específicamente a la familia Mamani García, la empresa de buses Palomo tuvo su esplendor en las décadas pasadas. Tras algunos años dorados ofreciendo una importante alternativa en el transporte de pasajeros entre Iquique y Oruro, en la actualidad observa su declive ante la mayor competencia de líneas nacionales, tanto bolivianas como chilenas. Buses Palomo ofrece solo dos salidas diarias desde lquique, un tráfico menor en el flujo diario de más de 20 viajes que ofrecen en conjunto las otras compañías. Según comenta un familiar: "Actualmente acá en lo que es la zona de Colchane hay un sólo empresario, bueno, microempresa ¿no? Y el que... el que está con los buses (Palomo), el único que hay, una sola persona acá en la zona..." (Entrevista con David, 12 de febrero de 2013)

Pese a esta actual menor incidencia en el mercado de pasajeros, el negocio del transporte ha posibilitado una importante acumulación de capital en la zona. La familia Choque, por ejemplo, también se integra a esta élite que ha reforzado su capital a partir de la expansión de estos negocios, aumentando la diferenciación social presente en las comunidades de origen. El testimonio de un pequeño transportista aymara, quien en la actualidad tiene un solo camión de su propiedad y ofrece servicios menores de fletes urbanos, critica las desventajas que enfrentan los pequeños transportistas en la competencia con las familias poderosas de Colchane: "Los Choque, ellos también po', crecieron harto, Gregorio Choque que se llaman... juuuh!, son grandes empresarios ahora, porque tiraron pa' arriba en familia... ¡Claro! (...) Eso no más, porque el resto andamos por ahí no más, un camioncito, dos camioncitos". (Entrevista con David, 12 de febrero de 2013).

La familia Choque también se ha destacado en la conformación de vínculos asociativos que defienden los intereses del grupo transportista aymara, según lo corrobora el mismo informante:

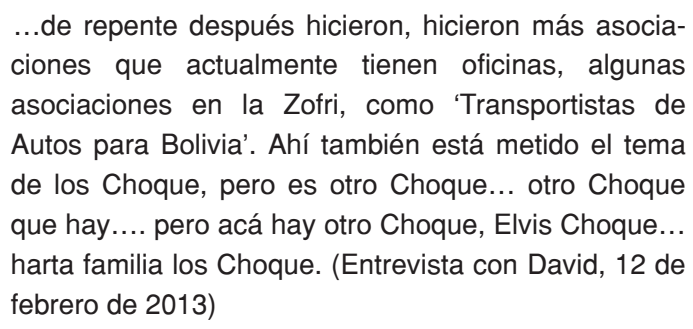

La conformación de estos capitales económicos, es acompañada de una acumulación de capital político, instalándose estas familias como nuevos actores de los sistemas políticos nacionales. Es el caso del mencionado empresario transportista Eddie Colque en la sub-alcaldía de Pisiga-Bolívar. Después de ejercer ese cargo entre 2009 y 2012, lo asumió su familiar María Colque Caniviri. Pero fue inmediatamente electo en otro puesto político relevante: "sub-alcalde originario”. Según sus palabras:

Entonces yo el 2009 estaba como sub-alcalde, 2009-2010. El año pasado estaba dejando, el 28-29 de abril. Ahora nuevamente me meten como sub-alcalde originario, pero qué voy a hacer: prestar un 
servicio al pueblo, con eso yo ya estoy completo, he pasado mis cargos... (Entrevista con Eddie, 10 de febrero de 2013)

El poder del "clan Colque" se aprecia con claridad al observar los nombres de las autoridades comunales elegidas el año pasado: corregidor, Jorge Colque; subalcalde municipal, Williams Colque; presidente, vicepresidente y secretario general del Comité Cívico de Pisiga, Daniel Colque, Ramiro Moya y Edwin Colque respectivamente. Secretaria del Comité de Vigilancia, Elizabeth Colque.

En el caso aymara-chileno también son relaciones familiares las que organizan el poder político local en torno a linajes tradicionales, tanto en la representación nacional como en los cargos "originarios". Vinculados asimismo al comercio transportista, los colchaninos han visto el traspaso de la alcaldía de Honorio Mamani a Teófilo Mamani el 2012. Aunque de signo político opuesto, son parte de la misma familia. Algo similar ocurre entre los candidatos a concejales: Doris Mamani, hermana del actual alcalde, presentó incluso demandas por cohecho ante el Tribunal Calificador de Elecciones (TRICEL) contra su pariente.

El actual cacique de Isluga es el padre del alcalde, en una fusión de intereses familiares que conjuga la representatividad originaria y la nacional. El caso de la mencionada familia García confirma las fusiones descritas: el alcalde de Camiña, Sixto García, solo ratifica el mismo mecanismo de legitimación. Sin intención de redundar, los actuales dirigentes comunales de diversos pueblos del interior eran familiares directos de casi todos los candidatos a concejal y alcalde de Colchane en la elección de 2012.
Pero junto con posicionarse dentro de su comunidad a partir del reconocimiento de un tercero extraétnico (asociaciones gremiales, sindicatos, ingreso a legitimidades políticas nacionales), estas élites refuerzan su posición intraétnica apelando a la resignificación e incluso refundación de estructuras étnicas de origen comunitario. Esta necesidad de reconocimiento comunitario de la élite local suele privilegiar dos mecanismos, ambos aplicados como reforzamiento de las jerarquías existentes:

a) Apropiación y reinvención del espacio ritual comunitario. Se aprecia la necesidad de reapropiar los espacios de autoridad tradicionales, generalmente en prácticas ceremoniales o simbólicamente relevantes, como la realización de anatas y carnavales. En ellas, son los grandes hombres quienes invitan a la comunidad a fiestas comunitarias que reafirman, a partir de enormes gastos ostentatorios, su prestigio y superioridad.

b) Mediación respecto del aparato del Estado y su oferta. Se observa la necesidad de controlar la entrega de beneficios y otras concesiones ofertadas por el Estado, a partir de la apropiación de las mediaciones políticas que permite el espacio nacional.

El caso de la mencionada familia García Mamani, en Colchane, resulta un buen ejemplo del primer mecanismo. Ante la desvalorización de las autoridades tradicionales, expresado en la muy escasa competencia por dar continuidad a la figura del alférez en el carnaval de Isluga, David García Mamani aceptó serlo el año 2012. A quien le corresponde dicho rol debe hacer de anfitrión, y por lo tanto cubrir todos los gastos de la fiesta comunitaria que se celebra en febrero de cada año. En una exube- 
rante muestra de derroche, este potlatch local reafirma el poder y la autoridad simbólica de la familia invitante, en una escena que apabulla la competencia social. La generación del prestigio a partir de la deuda colectiva así generada tiende a permear todas las actividades de la comunidad, quemando el excedente obtenido por las exitosas relaciones externas.

El alférez del 2012 explica la principal característica de este gasto ostentatorio ante la comunidad, refrendando que tras él se instala una gran familia. Se aprecia entonces la tendencia a ver reducida la práctica del $a y n i^{3}$ al reforzamiento de lazos de parentesco, perdiendo la anterior fuerza de cohesión comunitaria, en la que participaba la totalidad social en formas más solidarias que agonísticas:

\begin{abstract}
Eso es de parte mía, pero no sólo mía, todo el apoyo de mi familia, lo importante de todo es la familia, el núcleo familiar ya sean hermanos, primos y la costumbre que tengamos por acá, el famoso ayni que le llamamos nosotros. Eso es como (...) hoy día por mí, mañana por ti. De hecho por ejemplo mi hermana trajo una tarkeada 4 ... de Bolivia, que eso tiene un costo. El traslado también, entonces ella me lo regala, cariñosamente. El día de mañana cuando a ella le toque hacer algo, o al hijo de ella, yo tendré que también asumirlo... y así se hace. (Entrevista con David, 12 de febrero de 2013)
\end{abstract}

El segundo mecanismo, la mediación y reparto de la oferta oficial, se expresa con claridad en la entrega de beneficios a la comunidad, ya sea mediante la aplicación de criterios "particulares" en la distribución de subsidios o en el otorgamiento de licitaciones -con el mismo criteriopara ejercer de contratistas en obras públicas. La construcción de la nueva plaza de Colchane, gran infraestructura que implicó un gasto oficial de cientos de millones de pesos, la entrega de "pavimentos participativos", o la edificación de las nuevas dependencias del control fronterizo Colchane-Pisiga son un ejemplo de lo anterior. Todas ellas son ejecutadas directamente por empresas contratistas o subcontratistas ligadas a las grandes familias. Todas ellas, asimismo, vinculadas de una u otra manera al negocio transportista, ya sea directamente mediante flotas de camiones o buses, o indirectamente por la propiedad de la maquinaria necesaria para la mantención y construcción de caminos. ${ }^{6}$

Los mecanismos que distinguimos de manera analítica, como manifestación de relaciones solidarias o de reciprocidad en el cuerpo social, llevan aparejadas de modo consustancial movimientos agonísticos que conforman jerarquías y cadenas de deudas, que operan paralelamente en los campos político, económico y ritual (Mauss, 2008). Es decir que, las relaciones de reciprocidad y deuda generadas en el acontecimiento ritual de estas comunidades, pueden ser resueltas en el campo político del que también participa la oferta estatal ${ }^{7}$.

\section{La construcción del margen transportista}

Los procesos de acumulación que han permitido cierto auge transportista en Colchane y Pisiga, más la conformación de una elite del transporte al interior de las comunidades aymaras, tiene uno de sus correlatos en la conformación de un conjunto de pequeños transportistas (el margen), en efecto la mayoría, que no logran reunir el capital necesario para formar parte del pequeño grupo que logra constituir flotas de camiones y buses para el transporte de mercancías y personas (la elite). A continuación caracterizamos la forma en que se constituye y decae este margen del capital transportista, abriéndose hacia otras formas de 
actividad económica, algunas tradicionales y otras relacionadas con la formación de nuevos mercados globales, tal como ocurre actualmente con la producción y comercialización de la quínoa.

El ingreso a la actividad del transporte de mercancías o personas por parte de los aymaras de Colchane o familias de aymaras colchaninas está signada por el declive de la economía agropecuaria que diversos autores han venido señalando y que se ha traducido en el despoblamiento de las localidades en el interior (altiplano y cordillera) (Grebe, 1986; Van Kessel, 2003; Van Kessel, 1992 [1981]) ${ }^{8}$. Este proceso actualmente implica una presencia mayoritaria de la población indígena en las zonas urbanas de la costa o camino de ella, léase Pozo Almonte, Alto Hospicio e lquique, en el caso chileno. Más allá de los enfoques que sitúan aquí una esencialista pérdida de algún sustrato aymara, lo concreto es que efectivamente las antiguas comunidades anteriormente ancladas a unas economías y una organización fuertemente vinculada a un uso extensivo de territorios interiores, en la actualidad se presenta diseminada translocalmente, con actividades económicas en algunos casos complementarias, pero la mayor parte de las veces con gran parte de su población económicamente activa ya inserta en los mercados laborales de las grandes urbes, y con una cada vez más espaciada 'visita' a las localidades de origen en unos sentidos que se hacen casi exclusivamente rituales, ligados a la continuidad de algunas fiestas tradicionales como anatas y carnavales.

En este sentido, la memoria de David fija un tiempo en que la ganadería se constituía en el centro de la economía local, a la vez que activaba mecanismos comunitarios de explotación:
El pastoreo siempre fue, no igual, también se ha perdido eso, por lo mismo ha bajado el número de ganado, porque me acuerdo, pero siempre ha sido familiar en cuanto a ayudarse o pegar pa' ciertos lugares, porque mi mamá me contaba que antes, antes por ejemplo este tiempo, a partir de marzo, uno ya tenía que migrar, con los animales a la precordillera, al alto, a la precordillera, pero por, no por la quebrada, sino que más arriba... Entonces habían, habían, donde llegar, casa, pequeñas viviendas, entonces y se organizaba por ejemplo el pueblo ya yo voy, si voy, porque había que ir, había pasto por los ganados, en ese tiempo, entonces más que nada era la organización, que yo tenía 100, el otro juntábamos 500 cabezas y vamos a quedarnos por 3 días, lo que duraba el viaje, después venía y claro, eso era organizado y todos pa' un solo lado. (Entrevista con David, 12 de febrero de 2013)

Este escenario en que retroceden las actividades económicas tradicionales deja en principio un vacío que en cierta medida es ocupado por la actividad transportista. No planteamos que este haya sido el único sostén económico de las familias aymaras en las últimas décadas, más bien lo que puede constatarse de manera generalizada es la inserción en los sistemas educacionales y mercados laborales por parte de la población joven. De algún modo, la actividad del transporte supone una actividad con un anclaje bastante sustantivo en los territorios tradicionales, dado que hace uso de la nueva carretera pavimentada entre lquique y Oruro en Bolivia. De aquí se desprenden dos vías o trayectorias de acceso a esta actividad por parte de la población aymara.

Por un lado tenemos el acceso a esta industria protagonizada por los aymaras y sus familias ya migradas a las ciudades. Una vez insertos en los sistemas educacionales de las ciudades, y muchas veces sin tener un contacto previo con la industria transportista, acceden a trabajos y servicios vinculados a la econo- 
mía de la Zofri, que en una medida importante utiliza la ruta que atraviesa Colchane para internar mercancías hacia Bolivia. Una vez en la ciudad los jóvenes terminan la enseñanza obligatoria para luego estudiar carreras técnicas como mecánica u otras, que les acercan al mundo del transporte en diversos tipos de trabajos, muchas veces en la conducción de camiones. Esta trayectoria, similar a la que se sigue en el caso de la élite, puede ser representada por la familia de Apolinario Castro, de la localidad de Enquelga -a unos 20 kms. del pueblo de Colchane, todavía en la misma comuna- ilustra bien esta dinámica.

La familia nuclear de Apolinario está compuesta por él, su mujer y tres hijos varones que cursaron la enseñanza básica en el pueblo de Colchane. Una vez terminados estos estudios se desplazaron hasta lquique, en particular a Alto Hospicio, donde cursaron la enseñanza media y se vincularon al comercio en la Zofri en distintos trabajos vinculados a la labor transportista, desde cargadores de camión hasta como choferes. Como bien relata Apolinario, una diversidad de labores y esfuerzos que han conducido a la independencia económica de sus hijos y a su inserción en esta economía a través de la compra de un camión.

Se fueron pa' bajo ya po', allá está el bolsillo. Claro, les conviene a ellos porque allá encontrai la pega altiro, van allá ¿cómo se llama? a buscar trabajo... Con sus camioncitos, ya tienen sus camiones allá mucha gente, están cargando y descargando igual siguen en eso. De aquí todos estos se están quedando aquí, los jóvenes, mis hijos, todos se van descargando y cargando."

- ¿Y han comprado camiones?

"Sí, sí han comprado, si les va bien... Claro, al día cargaban, sacan casi 60 ó 80 lucas dicen porque, pero hay que pegarle weno po', no va a estar ahí sentao, si como a esta rato estaría descargando como 5 vehículos ya po'... Así que a descargar y fiuuuuu (emitiendo sonido) rapidito, fardos como por ejemplo se va rapidito el otro lo metí, como darle mayor, como darle mayor. (Entrevista con Apolinario, 15 de febrero de 2013)

Pese a que en Colchane destaca hoy sólo un empresario dedicado a los buses de pasajeros, los registros del Servicio de Impuestos Internos (SII) indican que de las 26 empresas inscritas en la comuna de Colchane al 2010, 20 corresponden al sector del comercio transportista, automóviles o repuestos (Biblioteca del Congreso Nacional, 2013).

Ahora bien, como hemos planteado más arriba, esta migración a las ciudades se explica o es correlato del despoblamiento de los pueblos del interior y el declive de la economía agropecuaria. En el caso concreto de esta familia esto se traduce en que la participación de los hijos en la economía que los padres están sosteniendo en Colchane se reduce a mínimos, retornando los hijos casi exclusivamente para las festividades o para invertir en el prestigio que supone el ser alférez de alguna celebración o fiesta. Apolinario manifiesta de modo constante las dificultades para mantener a los animales y una agricultura más allá de la subsistencia. Con todo, la trayectoria de esta familia permite intuir formas de movilidad social al interior de estos espacios, en términos de la conformación de una lógica de mercado que posibilita movimientos y nuevas formas de acumulación de poder que puede expresarse tanto en ámbitos económicos como político-rituales.

Por otro lado, tenemos una inserción en este mercado a través de un aprendizaje heredado familiarmente. La carretera que conecta Huara en la ruta 5 con Colchane y desde allí a Bolivia fue repavimentada durante la última década, 
pero tiene una existencia bastante anterior. El padre de Sergio Esteban se dedicaba a esta actividad ya en la década del 60, y pese a fallecer bastante joven alcanzó a transferir una suerte de 'saber transportista' a su hijo Sergio. La familia Esteban está vinculada al pueblo de Chijo, en las cercanías de Cariquima, siempre en la comuna de Colchane. En dicha localidad residen aún tíos, hermanos y hermanastros de Sergio, quienes terminan por constituir el resabio atado a la tierra de una familia que en su gran mayoría se encuentra ahora residiendo en Alto Hospicio e lquique.

Sergio tiene a esta altura ya más de 60 años, la mayor parte de los cuales los ha dedicado al transporte de mercancías, actividad en la que ha alcanzado a adquirir la propiedad de uno o dos camiones, pero que en ningún caso le han permitido llegar a formar parte de lo que hemos entendido como la elite transportista. Las razones de esto Sergio las ubica en la competencia desigual que se establece con las grandes empresas del transporte radicadas en lquique por una parte, y en la competencia injusta con los transportistas bolivianos por otra, que en sus palabras se desarrolla en términos muy informales y rehuyendo el pago de impuestos que transportistas como él no pueden dejar de sufragar. Sin embargo, de nuestra observación y conversaciones en terreno se puede inferir que una parte de la introducción de mercancías se produce de modo ilegal a través de pasos no autorizados en las inmediaciones de los pueblos aledaños a Colchane (donde está emplazado el complejo fronterizo binacional) ${ }^{9}$. Aquí la entrada de camiones con vehículos (conocidos como "cigüeñas") y otras mercancías se entiende son controlados por los comerciantes vinculados a las comunidades y territorios donde se ubican estos pasos informales ${ }^{10}$.
En ese contexto, el transporte de autos se erige como un negocio importante en la zona. El tráfico legal e ilegal desata asimismo las pugnas por la hegemonía sobre el territorio aymara, y descansa en grandes familias. El traslado de una "cigüeña"11 deja un ingreso bruto de US\$1.000 por vehículo puesto en Bolivia. Las ganancias aumentan si el tráfico se realiza por pasos no habilitados, utilidades no menores si se considera que cada "cigüeña" transporta un promedio de 10 vehículos $^{12}$. No es posible hacer una distinción clara acerca de la legalidad o ilegalidad de los productos transportados de esta manera, seguramente ambas posibilidades coexisten. Lo que nos interesa aquí es la coordinación de las economías, las redes y los usos que se hacen del territorio.

Con todo, las diversas formas de llevar a cabo estas empresas, ya sea de modo formal o informal, no han permitido o no han bastado para que los comerciantes como Sergio salgan del 'margen transportista' que describimos. Las posibilidades de una mayor acumulación económica se ven restringidas por la fuerte competencia local (aymara también), nacional y transnacional que se articula sobre esta ruta entre Chile y Bolivia. En el caso específico de Sergio, las décadas de dedicación a esta actividad tan exigente en términos físicos, le ha llevado a vender el vehículo de carga con que contaba, mientras se emplea ahora como pequeño transportista de fletes para una conocida multitienda de materiales de construcción y mueblería en Alto Hospicio.

En este escenario, el margen transportista observa, en el último desarrollo a nivel mundial del mercado de la quínoa, una estrategia de salida para una situación económica compleja en una de las comunas más pobres de Chile, confi- 
gurando una suerte de utopía que parte desde la viabilidad y eficiencia económica del cultivo de la quínoa en el altiplano y que termina en el consecutivo repoblamiento de sus territorios.

...y listo, no tuvimos otra fuente de trabajo, nada más que irnos pa' Cariquima, sembrar quínoa, pero la gran habilidad que nosotros tenemos es potenciar nuestro terreno... Pucha si hubiera posibilidades, se abriera una puerta que me dijera que pone la mitad pa' esta máquina y la otra mitad te la financio yo... shhhhiuu (emitiendo sonido) me voy encantado a Chijo, porque yo sé que soy agricultor, soy ganadero, yo soy chofer, camionero, ya me di vuelta por todo esto, fui a Calama, Antofagasta, donde no he vivido toda mi vida, pero en ningún lado me puedo sentir tan feliz igual que en mi pueblo... Yo voy a mi pueblo, descanso. De hecho hasta hoy día siembro quínoa, y siembro quínoa en Cariquima, tenemos terreno. (Entrevista con Sergio, 20 de febrero de 2013)

La confianza en la quínoa como elemento que permitirá el resurgimiento económico de estas zonas de altura, trata de un sentido común bastante extendido entre los diversos actores de estas comunidades, pasando incluso por los apoyos en términos de recursos y formación son allegados desde el aparato del Estado a través del municipio y del Instituto Nacional de Desarrollo Agropecuario (INDAP) ${ }^{13}$. En el marco de una economía del transporte que no produce excedentes suficientes para todos, la agricultura de la quínoa constituye el más nuevo imaginario de desarrollo en Colchane.

\section{Conclusión}

Hasta aquí hemos visibilizado los modos en que un conjunto de oportunidades estructurales, vinculadas al desarrollo del transporte y el comercio transfronterizo, han permitido la emergencia de una elite del transporte de mercancías y personas, y un conjunto de pequeños empresarios en sus márgenes, que con sus nuevas prácticas económicas han desplazado la centralidad que tenían en estos territorios las actividades ganaderas y agrícolas (Van Kessel, 1992), constituyendo así el actual núcleo simbólico y productivo de la zona. El nuevo empresariado del transporte ha desarrollado estrategias que le han permitido reconfigurar su dominio del poder local (tanto al lado chileno como boliviano de la frontera), utilizando en su provecho las nuevas relaciones de reconocimiento 'igualitario' en el marco del poder político nacional (Gundermann, Foerster \& Vergara, 2003), y las relaciones de índole 'jerárquica' que tradicionalmente han manejado dentro de sus comunidades.

De este modo, la elite que describimos opera a la forma de 'mediadores étnicos', que al mismo tiempo que ingresan a este nuevo mercado como actores diferenciados que pugnan por el control del tráfico transfronterizo con empresarios nacionales y transnacionales, controlan y/o canalizan a su favor las nuevas relaciones y beneficios que desde el Estado se dirigen hacia las comunidades locales y grupos étnicos. Son precisamente estas élites locales quienes absorben por ejemplo ayudas, subvenciones y concesiones para la mejora de los servicios e infraestructura en estas localidades. De este modo, observamos que las redefiniciones identitarias en proceso y el potenciamiento de las relaciones de mercado en estas comunidades, terminan por reforzar los linajes tradicionales que ya operaban en estos espacios, jerarquías supuestamente débiles a la hora de enfrentar su exposición a los patrones del mercado y la libre competencia. Todo lo contrario, la yuxtaposición de los poderes políticos, económicos y simbólicos al interior de las comunidades nos hablan más de una consolidación de estas jerarquías. 
Sin embargo, las trayectorias que describen el margen transportista nos hablan de cómo los individuos y familias actúan dentro de los mismos procesos y oportunidades de mercado que la zona franca y la nueva ruta han creado. Elite y margen participan conjuntamente de un campo de fuerzas que ya no se encuentra enclaustrado en el dominio de una localidad (reciente hegemonía de lo translocal), ni tampoco organizado en torno a una dinámica puramente económica o instrumental, sino que dibujando en sus prácticas la imbricación de las esferas de lo político, lo económico y lo ritual. Ciertamente, no se trata de la mera continuidad de estructuras organizativas y formas de transporte anteriores (por ejemplo, las observadas en el siglo XIX). Aquí estamos ante nuevas e importantes diferencias, como la influencia del contexto y el influjo de la globalización, el papel estructurante devenido de la constitución de las fronteras nacionales, los nuevos flujos de población resultantes entre los países y el factor tecnológico. Juntos conducen a la construcción de un nuevo fenómeno y a las relaciones sociales vinculadas a estos elementos.

\section{Notas}

${ }^{1}$ El problema de la tensión entre fuerzas individualistas y comunitarias en la cultura aymara han sido rastreadas diacrónicamente por Albó (2002).

${ }^{2}$ Cargos civiles con fuertes connotaciones religiosas que en la actualidad marcan diferencia con los nuevos dirigentes sindicales. Originalmente la principal función del jilakata era observar el desarrollo de los cultivos comunitarios y cuidarlos de los daños que podían ocasionar los animales en pastoreo. El cargo de jilakata es rotativo y de renovación anual, se realiza por una vez en la vida y constituye un deber ineludible (Delgado 2001; Zenteno, 2009; Jiménez \& Delgadillo, 2010).

${ }^{3}$ Sistema de trabajo colectivo basado en la reciprocidad entre familias, especialmente utilizado en actividades agropecuarias, construcción, y otras acciones ligadas a los ámbitos escolares y vecinales (Mendoza, 2007; De Munter, 2010). Para Murra, en la economía andina la reciprocidad entre parientes y vecinos comprendía actividades agrícolas, pastoriles y de construcción (Murra, 1975).

${ }^{4}$ Danza autóctona musicalizada con tarkas (pequeña flauta andina).

${ }^{5}$ Programa del Ministerio de Vivienda y Urbanismo de Chile, dirigido a personas organizadas en un comité de pavimentación y que habiten en un sector carente de pavimento. Se financia a través del aporte de Comités, Municipios y Sectorial (MINVU, 2013).

${ }^{6}$ Un fenómeno de características similares, de condensación del poder político en grupos de presión ligados al transporte, se aprecia en algunas alcaldías del Departamento de Santa Cruz, en Bolivia, en un fenómeno paralelo que es necesario indagar (Sandoval, Chirino \& Gutiérrez, 2013).

${ }^{7}$ Según De Munter, en el mundo andino las prácticas culturales -políticas, rituales, económicas- van entretejiendo a su vez diferentes reciprocidades que muestran facetas tanto positivas como negativas,

como por ejemplo la obligación de venganza y otras generadas por el don (De Munter, 2010). En la misma línea, Appadurai despliega un enfoque comparativo para entender este tipo de interrelaciones entre economía y sociedad, articulando al mismo tiempo sistemas de reciprocidad tradicionales a formas de relación modernas y/o capitalistas. Dice Appadurai: "Por supuesto existen muchas diferencias de escala, medios, contexto y objetivos entre la kula y los mercados de mercancías de entrega futura. Empero, las similitudes son reales $y$, como ya lo he apuntado, muchas sociedades crean terrenos especializados para las contiendas de valor, donde se comercian símbolos mercantiles especializados, y tal comercio influye, mediante las economías de estatus, poder o riqueza en los flujos mercantiles más mundanos." (Appadurai, 1991[1986], p. 70)

${ }^{8}$ Van Kessel propone que estos cambios constituyen un holocausto, pues implicarían "un abandono, general y total, de las raíces, cosmovisión y cultura aymaras". El ingreso en patrones modernizantes y el acceso a bienes materiales no tradicionales, dice, provocaría el "estrangulamiento" del mundo andino (Van Kessel, 1992 [1981]), p. 321). Grebe, por su parte, aunque también reconoce las modificaciones en el mundo aymara, expone una mirada diferente: "Se ha propuesto que una condición necesaria de la preservación de la identidad étnica es el aislamiento geográfico y social de la minoría étnica; y que el contacto cultural frecuente o residencia continuada en áreas urbanas (...) posibilitan la interacción de individuos pertenecientes a un grupo étnico con la sociedad mayor, enfrentándose en este caso al riesgo del debilitamiento o desintegración étnica. Esto debe ser reconsiderado" (Grebe, 1986, p. 206).

${ }^{9}$ Las principales mercancías internadas a Bolivia tanto legal como ilegalmente son los vehículos motorizados, maquinarias, línea blanca, electrónica, ropa usada, etc. 
${ }^{10}$ Dentro de la comuna de Colchane distinguimos dos pasos ilegales comúnmente usados para internar mercancías de contrabando hacia Bolivia. Por el lado norte de Colchane un paso por Pampa Parajalla (más conocido como Puerto Rico), y por el sur, en el sector de Cariquima, hay pasos por las localidades de Ancovinto y Panavinto, a un costado del salar Coipasa.

${ }^{11}$ Esta expresión refiere a las mercancías ocultas en la carga de un vehículo para el contrabando.

${ }^{12}$ Se debe consignar que en 2011 el gobierno de Evo Morales dictó la “Ley №133 de Saneamiento Legal de Vehículos", para regularizar

\section{Referencias bibliográficas}

Aduana Nacional de Chile. Estadísticas, 2012. Santiago. Recuperado de http://www.aduana.cl/prontus_aduana/site/ artic/20070418/pags/20070418155859.html

Appadurai, A. (1991 [1986]). Introducción: Las mercancías y la política del valor. En Appadurai, A. (ed.), La vida social de la cosas. Perspectiva cultural de las mercancías, (pp. 17-87). México: Grijalbo.

Albó, X. (2002). Identidad étnica y política. La Paz: Centro de Investigación y Promoción del campesinado CIPCA.

Biblioteca del Congreso Nacional (BCN). Reportes Estadísticos Comunales, 2013. Recuperado de http://reportescomunales.bcn.cl/ index.php/Colchane (Recuperado 4 de abril de 2013).

Bourdieu, P. (1997). Razones prácticas. Sobre la teoría de la acción. Barcelona: Anagrama.

Burguete, A. (2011). Municipalización del gobierno indígena e indianización del gobierno municipal en América Latina. Revista Pueblos y Fronteras Digital, 6(11), 38-88.

De Munter, K. (2010). Tejiendo reciprocidades: John Murra y el contextualizar entre los aymara contemporáneos. Chungara. Revista de Antropología Chilena, 42(1), 247-255.

Delgado, F. (2001). Simbiosis interzonal en las estrategias de autodesarrollo sostenible en ecosistemas de montaña: el caso del Ayllu Mujlli, Departamento de Cochabamba, Bolivia. (Tesis de doctorado). Universidad de Córdoba, Córdoba, España.

Grebe, M. (1986). Migración, identidad y cultura aymara: puntos de vista del actor. Chungara 16 y 17, 205-223.

Gundermann, H. (2003). Sociedades indígenas, municipio y etnicidad: La transformación de los espacios políticos locales andinos en Chile. Estudios Atacameños. Arqueología y antropología surandinas, (25), 55-77.

Gundermann, H., Foerster, R. \& Vergara, J. (2003). Mapuches $y$ aymaras. El debate en torno al recnocimiento y los derechos ciudadanos. Santiago de Chile: Ed. Universidad de Chile/PREDES/RIL.

Jiménez, Z. \& Delgadillo, J. (2010). Investigación participativa en gestión territorial indígena originaria y campesina: Ganadería campesina y gestión territorial de la comunidad Tallija-Confital, Ayllu Aransaya provincia Tapacari, Cochabamba-Bolivia. Cochabamba: AGRUCO. PIPRGT. PLURAL. los ingresados ilegalmente al país. En sus cuatro meses de aplicación se registraron 67.077 vehículos, que ingresaron en el programa y se legalizaron ante la Aduana Nacional de Bolivia (Zamorano, 2012).

${ }^{13}$ Dos son los ámbitos que los comerciantes y propietarios de tierra distinguen como importantes para el desarrollo de los cultivos de quínoa en Colchane. El acceso a créditos blandos que les permitan invertir en maquinarias para así llevar a cabo cultivos más intensivos, y la diversificación de los agentes que compran su producción de modo de no depender casi en exclusiva de los compradores bolivianos que actualmente dominan este comercio.

Mauss, M. (2008 [1950]). Essai sur le don. Forme et raison de l'échange dans les societés archaiques [1924] En Mauss, M. (Ed.). Sociologie et Antropologie (pp. 145-284). Paris: PUF.

Mendoza, M. (2007). Descentralización, construcción ciudadana y capital social en Bolivia. Un análisis social, político y económico con estudios de caso de la zona andina y consideraciones sobre autonomías. La Paz: PIEB.

Ministerio de Vivienda y Urbanismo (MINVU) (2013). Recuperado de http://www.minvu.cl/opensite_20070308155628.aspx

Murra, J. (1975). Formaciones económicas y políticas del mundo andino. Lima: Instituto de Estudios Peruanos.

Orellana, R. (2009). Municipalización de pueblos indígenas en Bolivia: impactos y perspectivas. En Assies, W., Van der Haar, G. \& Hoekema, A. (Eds), El reto de la diversidad. Pueblos indígenas y reforma del Estado en América Latina (pp. 315-340). México: El colegio de Michoacán.

Perreault, T. (2006). From the Guerra del Agua to the Guerra del Gas. Resource Governance, Neoliberalism and Popular Protest in Bolivia. Antipode 38(1), 150-172.

Pimentel, G., Rees, C., de Souza, P. \& Arancibia, L. (2011). Viajeros costeros y caravaneros. Dos estrategias de movilidad en el Período Formativo del desierto de Atacama, Chile. En Núnez, L. \& Nielsen, A. (Eds.) En Ruta. Arqueología, Historia y Etnografía del tráfico sur andino (pp. 43-81). Santiago: Encuentro.

Richard, N., Moraga, J. \& Saavedra, A. (2016). El camión en la Puna de Atacama (1930-1980): mecánica, espacio y saberes en torno a un objeto técnico liminal. Estudios Atacameños 52, 177-199. http://dx.doi.org/10.4067/S0718-10432016005000005.

Richard, N., Galaz-Mandakovic, D., Carmona, J. \& Hernández, C. (2018). El camino, el camión y el arriero. La reorganzación mecánica de la puna de Atacama (1930-1980). Historia 396. 8(1), 163-192.

Sandoval, D., Chirino, F. \& Gutiérrez, J. (2013). Redes económicas y sociales: reconfiguraciones en el transporte interprovincial en Santa Cruz. La Paz: Programa de Investigación Estratégica en Bolivia (PIEB).

Tassi, N. (2015). Pensando el mundo desde los márgenes: la expansión cosmológica y económica de los comerciantes aymaras en Bolivia. En Di Giminiani, P., González, S., Murray, M. \&, Risor, 
H. (Eds.) Tecnologías en los Márgenes: Antropología, Mundos Materiales y Técnicas en América Latina (pp. 43-66). México: Bonilla Artigas Editores.

Tassi, N., A. Hinojosa, \& Canaviri, R. (2014). La economía popular en Bolivia: tres miradas. La Paz: Vicepresidencia del Estado, Presidencia de la Asamblea Legislativa Plurinacional.

Van Kessel, J. (1992 [1981]). Holocausto al progreso. Los aymara de Tarapacá. La Paz: Hisbol.

(2003). La empresa salitrera: el primer milagro económico chileno y el último capítulo de la historia de la comunidad aymara en Tarapacá. Cuadernos de Investigación en cultura y tecnología andina, № 15. IECTA-Chile. Recuperado de http://www.iecta.cl/ biblioteca/cuadernos/html/cuaderno_15.htm

Yánez, N. \& Molina, R. (2008). La gran minería y los derechos indígenas en el norte de Chile. Santiago de Chile: LOM Ediciones

Zamorano, Y. (2012). Análisis Estadístico del Programa de Saneamiento Legal de Vehículos 2011. Base de datos de los vehículos saneados según la Ley $N^{\circ} 133$. (Documento de trabajo de la Aduana Nacional de Bolivia). Recuperado de http://www.aduana.gob.bo/ An\%C3\%A1lisis\%20Programa\%20de\%20Saneamiento\%202011.pdf

Zenteno, H. (2009). Acercamiento a la visión cósmica del mundo andino. Revista Punto Cero 18(14), 83-89. 